\title{
ENTREPRENEURIAL SUCCESS AND FAILURE: CONFIDENCE AND FALLIBLE JUDGMENT
}

\author{
Robin M. Hogarth* and Natalia Karelaia** \\ * ICREA and Universitat Pompeu Fabra, Department of Economics and Business, Ramon \\ Trias Fargas, 25-27, 08005 Barcelona, Spain, Tel: + 34542 2561, \\ robin.hogarth@upf.edu. \\ ** INSEAD, Boulevard de Constance, 77305 Fontainebleau, France, Tel: + 331607245 11, \\ natalia.karelaia@insead.edu.
}

The authors' names are listed alphabetically. They have benefited from the helpful comments of Daniela Grieco, Don Moore, Kanchan Mukherjee, Rodolfo Prieto, Jack Soll, and seminar participants at Carnegie Mellon University, Universitat Pompeu Fabra, INSEAD, and London Business School. This research was financed partially by grants from the Spanish Ministerio de Educación y Ciencia and the Swiss National Science Foundation. 


\begin{abstract}
Excess entry - or the high failure rate of market-entry decisions - is often attributed to overconfidence exhibited by entrepreneurs. We show analytically that whereas excess entry is an inevitable consequence of imperfect assessments of entrepreneurial skill, it does not imply overconfidence. Judgmental fallibility leads to excess entry even when everyone is underconfident. Self-selection implies greater confidence (but not necessarily overconfidence) among those who start new businesses than those who do not and among successful entrants than failures. Our results question claims that "entrepreneurs are overconfident" and emphasize the need to understand the role of judgmental fallibility in producing economic outcomes.
\end{abstract}

Keywords: Excess entry; fallible judgment; overconfidence; skill uncertainty; entrepreneurship.

JEL classification: D80, L26, M13. 


\section{Introduction}

The phenomenon of excess entry refers to the observation that "too many" entrepreneurs elect to enter certain industries and that many subsequently fail. In the U.S., for example, Small Business Administration datasets suggest that, in any year, 10\%-12\% of all firms are new entrants (Dennis 1997). In Europe, Geroski (1995) documented that up to 100 new firms enter each of the 87 classifications of British manufacturing industries annually. Individuals as well as firms create many new enterprises. However, it has been estimated that $75 \%$ of new businesses do not survive more than five years (Bernardo and Welch 1997). Investigating the difference between closure and failure, Headd (2003) reports that roughly $50 \%$ of firms exit within their first four years, and about two-thirds of these are unsuccessful at closure (as defined by their owners). This implies an overall failure rate of $33 \%$.

The causes of this phenomenon have been attributed to both economic and psychological factors. As to the former, it has been argued that entrepreneurs essentially face lotteries with highly skewed payoffs. Thus, whereas probabilities of success are low, the accompanying payoffs are high. It is rational for entrepreneurs to accept gambles with positive expected utility even though only a minority can succeed.

The psychological explanation has focused on the notion of overconfidence. For example, Cooper, Woo, and Dunkelberg (1988) found that $81 \%$ of a sample of 2,994 entrepreneurs believed that their chances of success were at least $70 \%$, and one-third believed they were certain to succeed. When asked about others, however, only $39 \%$ believed that the chances of any business like theirs succeeding were $70 \%$ or more. Another recent survey (Koellinger, Minatti, and Schade 2007) documents a negative relation between self-reported levels of entrepreneurial confidence and the survival chances of new entrepreneurs across countries. In addition to surveys, the psychological evidence favoring overconfidence is also grounded in controlled experiments (Camerer and Lovallo 1999; Moore and Cain 2007).

If overconfidence leads to excess entry, much could be gained if entrepreneurs learned to modify their beliefs. Indeed, this is the implicit recommendation of the psychological evidence just cited. However, if entrepreneurs are not really overconfident, this advice could be counter-productive. In this paper, we do not question that the judgments of entrepreneurs are imperfect or fallible. However, fallibility does not necessarily imply overconfidence. Indeed, equating the two can lead to erroneous implications.

To motivate our argument, imagine a situation where entrepreneurs are considering entering a market where success can only be achieved by those whose skill level, $Y$, is above a specific threshold, $y_{c}$. Imagine further that each entrepreneur makes a judgment or receives 
a signal, $X$, about his/her skill level that is imperfectly correlated with $Y$. However, there is no systematic bias, that is $\mathrm{E}[Y]=\mathrm{E}[X]$. In this case, some entrepreneurs will believe that their skill level lies above $y_{c}$ when, in fact, it does not, and their decision to enter the market will lead to excess entry. At the same time, others will believe that their skill level lies below $y_{c}$ when, in fact, it is greater. But, if the latter take no action (i.e., they decide to stay out), no associated outcomes can be observed. In other words, when entrepreneurs rely on the imperfect relation between assessed and true skill to take action, we are guaranteed to observe excess entry but not its converse, missed opportunities.

It is important to note that this scenario also captures the essence of many other situations where individuals accept risk by betting on their skills. Consider, for example, career decisions, selecting research projects, strategic industrial choices, and so on. These examples also typically involve ambiguity in that probabilities of outcomes are neither known nor easily quantified.

In this paper, we first review previous explanations of excess entry and related literature and note that overconfidence can be considered in both absolute and relative terms. Next, we specify the model sketched above in greater detail and also show how the differential validity of signals indicating skill levels should affect entry decisions but that this depends on market capacity. We go on to illustrate our model's implications through simulations. In short, when signal validity is imperfect, excess entry can occur without systematic overconfidence in a population of potential market entrants. At the same time, there are also many missed opportunities. Moreover, different levels of overconfidence (absolute and relative) will be observed between sub-populations that enter and do not enter the market as well as among successful and unsuccessful entrants. Whereas the latter are inevitably shown to be overconfident, many of the former are too. The interpretation of empirical studies of entrepreneurial overconfidence is thus fraught with difficulties. We conclude by emphasizing distinctions between different types of overconfidence, the need to understand the role of judgmental fallibility in producing economic outcomes, and implications for the training of future entrepreneurs.

\section{Previous explanations and related literature}

Explanations of the excess entry phenomenon have been grounded in both economics and psychology. The standard economic story is that high profits attract entry and entrants bid away these profits, eventually pushing the industry into long run equilibrium with no excess returns and a given number of firms. Similarly, whenever profits fall below "normal" 
levels, exit occurs and this depopulation of the industry raises profitability for the survivors back to equilibrium. From this perspective, failures are "hit and run" entrants that have only a small chance of success in the limited period when the industry exhibits extra profits.

Alternatively, starting a business can be framed as facing a gamble where the probability of winning is extremely low but the payoff for success is large. This explanation enlarges the former perspective by accounting for uncertainty, information, and risk attitudes in determining entry decisions.

A further hypothesis is that entrepreneurs are more risk seeking than non-entrepreneurs. However, the empirical literature provides conflicting results. The general conclusion is that entrepreneurs do not differ in risk attitudes from the overall population (Brockhaus 1980; Masters and Meier 1988; Palich and Bagby 1995) and may even be more risk averse than non-entrepreneurs (Miner and Raju 2004). ${ }^{1}$ Alternatively, entrepreneurs may simply accept risky business situations as given (Sarasvathy, Simon, and Lave 1998) or assess opportunities and threats differently from non-entrepreneurs (Norton and Moore 2002).

Psychological explanations for excess entry are based on the notion of overconfidence (Kahneman, Slovic, and Tversky 1982; Klayman, Soll, Gonzalez-Vallejo, and Barlas 1999). Specifically, individuals overestimate their chances of success and erroneously expect to succeed where others will fail. Thus, the decision to enter may be taken even if negative industry profits are expected.

Recently, Moore and Healy (2008) clarified conceptual confusion surrounding the concept of overconfidence by distinguishing three distinct meanings. First, people can be overconfident in estimating their ability to do something. For example, a person might overestimate his ability to run a Marathon within a certain time. Moore and Healy call this overestimation and it is important to note that it is not universal. A robust finding is that people tend to overestimate their own skill on hard tasks but underestimate it on easy tasks (Burson, Larrick, and Klayman 2006; Moore and Cain 2007). One explanation is that because judgments of skill typically involve error, they are liable to be regressive (Dawes and Mulford 1996; Erev, Wallsten, and Budescu 1994).

Second, a person might express overconfidence in ability relative to others; for example, the belief that one can run the Marathon faster than, say, $80 \%$ of a specific population. Moore and Healy call this overplacement. It is also known as the "better-thanaverage" effect whereby people judge their abilities in familiar domains, such as driving, as 
being superior to that of the "average" person (Svenson 1981). At the same time, however, there is a tendency to judge oneself as below average in unfamiliar (and therefore hard) tasks such as juggling (Kruger 1999). Also, as Hoelzl and Rustichini (2005) demonstrate, this type of overconfidence may be moderated when people are required to make incentive-compatible choices as opposed to expressing opinions.

Third, people can be overconfident when estimating future uncertainty; for example, when providing confidence intervals for forecasts of, say, sales that subsequently turn out to be too narrow (see, e.g., Alpert and Raiffa 1982). Moore and Healy call this overprecision. Interestingly, Wu and Knott (2006) suggest that, whereas entrepreneurs might not be overconfident in assessing market demand, they do overestimate their ability to manage ventures successfully.

Camerer and Lovallo (1999) tested the overconfidence hypothesis experimentally in a game designed to mimic entry decisions. Specifically, $N$ participants decide simultaneously to enter a market with a pre-announced capacity of $c$ participants $(N>c)$ where payoffs depend on participants' ranks (i.e., of those choosing to enter, the highest-ranked participant receives the largest payoff, the lowest-ranked participant, the smallest payoff). Ranks were established in two ways at the end of the experiment (i.e., after all choices had been made): at random, and on the basis of relative performance on a test (skill). When making entry decisions, however, participants knew how ranks would be established, i.e., at random or according to relative skill. Camerer and Lovallo tested for overconfidence by comparing entry rates between the random and skill conditions and found significant effects - greater entry under the skill condition.

Camerer and Lovallo claim that their results are consistent with overconfidence in that, whereas participants had accurate expectations concerning the number of competitors, the differential entry rates between the skill and random conditions provided evidence of overconfidence in their relative skill. $^{2}$ As we demonstrate below, however, the decision to act on the basis of an imperfect signal, but not to act in the absence of a signal, does not necessarily imply overconfidence, either in the sense of overestimation or overplacement.

\footnotetext{
${ }^{1}$ Parenthetically, this literature relies on biased samples in that studies only include "successful" survivors, i.e., those unsuccessful entrepreneurs who have left the market are excluded.

${ }^{2}$ Camerer and Lovallo also asked their participants to estimate the number of entrants on each round. For most participants, forecasts were unbiased.
} 


\section{A model of entrepreneurial entry}

To illustrate how the validity of signals indicating skill levels affects entry decisions, we present a simple model of entry behavior. We then use the model to quantify the observed level of overconfidence (both in terms of overestimation and overplacement) among entrepreneurs who decide to enter the market and among those who stay out. We emphasize the differences between those who enter and succeed and those who fail on entry. The model also provides insights on missed opportunities and how these could be reduced. Of course, there are more detailed formal models of the evolution of industry (e.g., Jovanovich 1982; Klepper 1996). However, our purpose is to illustrate the effect of judgmental fallibility and confidence on entry. The model presented here serves this purpose well.

We assume that an entrepreneur's success in entering a market depends on her managerial skill, $Y$. However, this is not known precisely by the entrepreneur and has to be estimated. Denote the estimate by $X$. On any given occasion, therefore, the entrepreneur is overconfident in her skill (in the sense of overestimation) if $x>y$ and underconfident if $x<$ $y^{3}$ However, assume that, on average, the population of entrepreneurs is neither over- nor underconfident, i.e., $\mathrm{E}[Y]=\mathrm{E}[X]$, and that the imperfect relation between $Y$ and $X$ can be captured by the correlation between them, $\rho_{x y}$, that we label signal validity. For simplicity, we assume that $X$ and $Y$ are standardized normal variables, $\mathrm{N}(0,1)$.

Within this set-up, we define overplacement as occasions when $y<\mathrm{E}[Y]$ and $x>\mathrm{E}[Y]$. That is, the entrepreneur is overconfident in the sense of overplacement if her true skill $y$ is inferior to the average skill in the population and her estimate of own skill $x$ surpasses the average skill. The proportion of overplacement, i.e., entrepreneurs who erroneously consider themselves to be "better-than-average", is defined by the joint probability $P\{y<E[Y] \cap x>E[Y]\}$ and is a decreasing function of signal validity, $\rho_{x y} \cdot{ }^{4}$ This definition captures the notion of "better-than-average." However, overplacement can also be defined relative to any fractile of the distribution of $Y$ and not just the median.

Suppose further that success or failure depends on whether the level of skill exceeds a threshold, or success cut-off point, $y_{c}$, located at a specific fractile of the distribution of $Y$. This threshold captures market capacity: larger values of $y_{c}$ correspond to more stringent

\footnotetext{
${ }^{3}$ We use upper case letters to denote random variables, e.g., $Y$, and lower case letters to designate specific values, e.g., $y$. As exceptions to this practice, we use lower case Greek letters to denote random error variables, e.g., $\varepsilon$, as well as parameters, e.g., $\rho$.

${ }^{4}$ To aid intuition in understanding the importance of signal validity, $\rho_{x y}$, in overplacement, note that if $X$ and $Y$ were identical then, by our definition, overplacement would be impossible.
} 
markets where capacity (and therefore the rate of success) is smaller. Overplacement relative to the success cut-off point, $y_{c}$, is defined by the joint probability $P\left\{y<y_{c} \cap x>y_{c}\right\}$.

When does market entry take place? What probability of success does an individual entrepreneur require to enter a market? This question can be reframed by asking what level of estimated skill, $x_{c}$, would leave an entrepreneur indifferent between entering or staying out of the market.

Assume that if the entrepreneur enters the market and loses (i.e., if $y<y_{c}$ ), a loss of $K$, the initial investment, is incurred. On the other hand, if successful (i.e., $y>y_{c}$ ), the entrepreneur's payoff is $f\left(y-y_{c}\right)-K$, that is a function of the extent to which $y$ exceeds $y_{c}$ less the investment, $K^{5}$ We assume that the payoff of the decision to stay out is equal to zero. Thus, entrepreneur $i$ is indifferent between entering and not entering the market if her expected payoff of entry is equal to zero:

$$
\mathrm{E}\left[\text { entry } \mid X=x_{i}\right]=-K \int_{-\infty}^{y_{c}} f_{Y \mid X}\left(y \mid x_{i}\right) d y+\int_{y_{c}}^{\infty}\left(y-y_{c}-K\right) f_{Y \mid X}\left(y \mid x_{i}\right) d y=0,
$$

where the conditional pdf $f_{Y \mid X}\left(y \mid x_{i}\right)=\frac{f_{X, Y}\left(x_{i}, y\right)}{f_{X}\left(x_{i}\right)}$ is a normal density with mean $\frac{\rho_{x y} \sigma_{y}}{\sigma_{x}} x_{i}$ and variance $\left(1-\rho_{x y}^{2}\right) \sigma_{y}^{2}$.

The solution of equation (1) determines $x_{i}^{*}=x_{c}$, i.e., the entry decision cut-off point. Thus, if $x_{i}>x_{c}$, the decision is to enter the market; and if $x_{i}<x_{c}$, to stay out (all other things being equal). The probability of entry thus increases when $x_{c}$ decreases and the location of $x_{c}$ can vary depending on both risk attitudes and the expected economic consequences of different situations. For the purpose of this paper, however, we assume risk neutrality.

Because closed-form solutions cannot be found for equation (1), we have simulated three scenarios (see also the Appendix). These differ on the cost of entry, $\mathrm{K}$, with $\mathrm{K}=0.1$, 0.4, and 1.0, and results are depicted in the three panels of Figure I. Within each scenario, we vary both signal validity, $\rho_{x y}$ and the success cut-off point, $y_{c}$. The curves depict the probability of entry as a function of $\rho_{x y}$. One curve corresponds to each level of $y_{c}$.

\footnotetext{
${ }^{5}$ For simplicity we assume that $f\left(y-y_{c}\right)=\left(y-y_{c}\right)$. Monotonic changes in the form of this function will not alter the qualitative implications of the model.
} 
Insert Figure I about here

Qualitatively, the graphs show that signal validity determines the number of entrants and that this, in turn, depends on market capacity. In particular, it is important to distinguish between cases where market capacity is small (operationalized in our model by high values of the success cut-off point, $y_{c}$ ), as opposed to large (low $y_{c}$ ). For the former (consider, e.g., the restaurant business in a small provincial town), the number of market entrants increases as signal validity increases - i.e., in tough markets, entrepreneurs need a more valid signal to enter the market. For the latter (consider, e.g., the restaurant business in a large tourist city), the number of entrants decreases as signal validity increases. However, when $K$, the investment needed to enter is high, an increase in signal validity triggers more entry even in relatively large markets (i.e., relatively low values of $y_{c}$; compare the curves corresponding to the same $y_{c}$ 's in the left, central and right hand-side panels of Figure I). Further interpretation of Figure I is provided in the Appendix.

It is also useful to think about signal validity as a proxy for "skill uncertainty" (i.e., uncertainty about one's skill) that may be due to technological or market changes in the industry or even lack of experience on the part of the entrepreneur. One implication of our model is that, when cost of entry is low, diminishing uncertainty increases the rate of entry in the toughest (i.e., stringent) markets but decreases it in larger markets. When cost of entry is relatively high, however, lower uncertainty implies more entry in all but the largest markets.

As another implication, consider the experimental set-up of Camerer and Lovallo (1999) that involved a known, small market capacity, no cost of entry but high cost of failure. In this situation, more entrepreneurs should enter the market as signal validity increases. Thus - contrary to the assertion of Camerer and Lovallo - the observation of a higher entry rate being associated with an imperfectly valid as opposed to no signal (i.e., between the skill and random conditions), does not necessarily imply overconfidence.

Model simulations. As a general statement, our model predicts the observation of excess entry even if there is no overconfidence in the population of potential entrepreneurs (in the sense of estimation), i.e., $\mathrm{E}[Y]=\mathrm{E}[X]$, provided signal validity is imperfect, i.e., $\rho_{x y}<$ 1. We now show why it happens and then further investigate the model to refine the above statement and to illuminate more specific points. In doing so, we treat $x_{c}$ as endogenous (i.e., determined by equation (1)). 
First, we examine how different values of signal validity or skill uncertainty, $\rho_{x y}$ affect rates of market entry and excess entry - that is, $P\left\{x>x_{c}\right\}$ and $P\left\{y<y_{c} \mid x>x_{c}\right\}$.

Second, whereas much has been said about excess entry, less attention has been paid to missed opportunities, that is, businesses that would have been successful had entrepreneurs decided to enter the market instead of staying out of it (Moore, Oesch, and Zietsma 2007). How important are these (i.e., $P\left\{y>y_{c} \mid x<x_{c}\right\}$ )?

Third, we assess the observed levels of overconfidence in the senses of both overestimation and overplacement. In particular, what proportion of entrepreneurs overestimates their absolute skills (i.e., for whom $x>y$ )? What proportion overplaces themselves relative to others (i.e., for whom $y<\mathrm{E}[Y]$ and $x>\mathrm{E}[Y]$ )? Does confidence differ between those who do and do not enter the market, and between successful and unsuccessful entrants? On average, do entrepreneurs in different categories such as entrants, non-entrants, successful entrants, excess entrants and failures overestimate or underestimate their skills? To answer this latter question, we evaluate, separately for each category, the differences between average estimated and true skills, i.e., $(\bar{x}-\bar{y})$.

Finally, we ask what happens when entrepreneurs are, on average, over- and underconfident. For example, does excess entry occur even in the presence of systematic underconfidence among potential entrepreneurs (i.e., when $\mathrm{E}[X]<\mathrm{E}[Y]$ )?

To investigate these issues, we simulated populations of 100 entrepreneurs drawing estimates of own skill $(X)$ and values of true skill $(Y)$ from correlated normal distributions with fixed parameters. For each population, we calculated entry rate, excess entry rate, missed opportunities, the proportions of overestimation within different categories (i.e., entrants, non-entrants, successful entrants, and excess entrants), the proportions of overplacement within the same categories, and the proportions of overplacement among those entrepreneurs who overestimate their skills in absolute terms. In addition, we calculated the magnitude of over- or underestimation (i.e., the difference between estimated and true skill) within each category. We repeated the simulation 50,000 times for each combination of parameters. Thus, the results correspond to the average of 50,000 populations of entrepreneurs.

Insert Table I about here 
Signal validity and excess entry. Table I illustrates the effect of changes in signal validity, $\rho_{x y}$, when the population of potential entrepreneurs is well calibrated, i.e., when the means of estimated and true skill coincide, $\mathrm{E}[X]=\mathrm{E}[Y]$. For each combination of the simulation parameters, the entry cut-off, $x_{c}$ is found from the indifference equation (1). We provide results for three hypothetical markets (three panels in Table I) of different capacity, ranging from large (left panel, $y_{c}=-0.5$, equivalent to the $31^{\text {st }}$ percentile of the population), medium (middle panel, $y_{c}=0.5$, equivalent to the $69^{\text {th }}$ percentile of the population), to small (right panel, $y_{c}=1.0$, equivalent to the $84^{\text {th }}$ percentile of the population). In this example, the cost of entry, $K$ is 0.1 .

In the largest market, almost all (99.9\%) potential entrepreneurs decide to enter the market when no valid signal about skill is available, i.e., when $\rho_{x y}=0$ (Table I, line 1). The probability of entry in this market decreases gradually as signal validity increases. In smaller markets, the probability of entry increases as signal validity grows larger. For example, in the smallest market (right panel), only $0.1 \%$ enter when no valid signal is available, and $6.7 \%$ enter when signal validity increases to 0.9 . Excess entry (the probability of failure given entry - line 2) is positive across all the situations that we examine (reflecting the imperfect nature of the signal), but decreases as the signal becomes more valid (e.g., from $84.4 \%$ to $8.0 \%$ in our most stringent market, right panel). The implication is that the imperfect relation between estimated and actual skill ensures excess entry even at the lowest levels of skill uncertainty, i.e., when signal validity, $\rho_{x y}$ is close to one.

As for missed opportunities (line 3), the increase of signal validity from 0.0 to 0.9 decreases the proportion of missed opportunities by $51 \%$ (69.2 to 34.0) in our largest market (left panel) and by $34 \%$ (15.9 to 10.4) in our smallest market (right panel).

Signal validity and overconfidence. The data on proportions of overconfidence in the sense of overestimation (line 4) reveal several trends. First, these proportions are much greater among entrepreneurs who enter the market than those who stay out. In particular, across all situations presented in Table I, more than $50 \%$ of entrants overestimate their skill while at most $50 \%$ of non-entrants do so. More confident individuals self-select into the market. Second, overestimation is greater among failures (excess entrants) than among successful entrants. In fact, all failures are overconfident in the sense of overestimation in our most and moderately stringent markets (right and central panels). 
At one level it appears that excess entry is due to overconfidence in that a greater proportion of entrepreneurs who fail are overconfident compared to those who succeed. However, it is important to recognize that this observation is entirely consistent with a model in which population estimates of entrepreneurial abilities are not systematically biased (i.e., overconfident), simply imperfect.

Do different groups of entrepreneurs, on average, overestimate or underestimate their skills? Line 5 presents the average difference between estimated and true skills $(\bar{x}-\bar{y})$ within different categories and confirms the trend concerning overestimation. There is selfselection in that entrants, on average, overestimate their skills (positive or zero values of the difference $\bar{x}-\bar{y}$ ), whereas non-entrants underestimate their skills (negative values or zero). As for excess entrants (failures), they overestimate their skills more than successful entrants. In particular, excess entrants' estimates of own skill are 3.6 standard deviations above their true skill in the smallest market when outcomes are close to random occurrences (right panel, first column). However, this decreases to 0.9 standard deviations when signal validity, $\rho_{x y}$, increases to 0.9 (same panel, last column). In both cases, the inflations of self estimates are above those corresponding to successful entrants: 1.8 and 0.1 standard deviations, respectively. The trend is similar in our least and moderately stringent markets (left and central panels).

It is illuminating to compare the magnitude of average miscalibration among successful entrants in different markets. While this subgroup of entrepreneurs is underconfident in their skills in the largest market (left panel, first three columns), they are overconfident in the smallest (right panel). Importantly, the magnitude of miscalibration (both in the direction of under- and overestimation) decreases among both successful entries and failures when signal validity, $\rho_{x y}$, increases. Thus, in surveys measuring absolute confidence of active entrepreneurs in stringent markets, the presence of overconfidence is almost guaranteed even when there is no bias in the population of potential entrepreneurs. However, it would be misleading to extrapolate this conclusion to less stringent markets, where successful entrepreneurs may even be underconfident. In addition, observed overconfidence will be especially high when measured in conditions of large skill uncertainty, e.g., after a technological or product change.

The analysis of confidence in terms of overplacement (line 6) leads to similar qualitative conclusions as the analysis of overestimation presented above. In particular, there are proportionally more individuals who erroneously believe that they are better than the 
success cut-off fractile among entrants than non-entrants. Most revealing is the comparison of overplacement between successes and failures (excess entrants). In our tougher markets (central and right panels), all failures believe that they are better than the success cut-off fractile when, in fact, they are not. None of the successful entrants do so in any situation that we consider. Again, although surveys measuring relative overconfidence of active entrepreneurs in an industry might suggest that overconfidence in the sense of overplacement is driving entry and excess entry, the observations are also consistent with just simple judgmental fallibility (and not a systematic bias).

Finally, are the two types of overconfidence (overestimation and overplacement) related? How often do those who overestimate their skill erroneously believe that they are "better-than-average" or better than the success cut-off? We report the probability of overplacement given that individuals overestimate their skill on line 7 of Table I. Overestimating own skill naturally increases the chances of overplacing yourself relative to your peers (compare lines 6 and 7, "All potential entrants"). Overall, the proportions of overplacement given overestimation are far from being equal to one - both in the population of potential entrepreneurs and among entrants. This is especially true at higher levels of signal validity. To conclude, overestimation does not necessarily imply overplacement and the two types of overconfidence should be measured separately.

The effect of systematic miscalibration in the population. The above simulations assumed that there was no systematic bias in skill estimates at the level of the population of potential entrepreneurs. Would such bias change the implications of our model? To illustrate, we shift the mean of estimated skill, $\mathrm{E}[X]$ away from the mean of true skill, $\mathrm{E}[Y]$ in the simulations. Specifically, we vary the mean of estimated skill from -0.9 (underconfidence in the sense of underestimation) to 0.9 (overconfidence in the sense of overestimation). The results for the same three markets (of low, moderate, and high capacity) for a fixed signal validity, $\rho_{x y}$ of .5 and the cost of entry, $K$ of 0.1 are presented in Table II. For each set of parameters, the entry cut-off, $x_{c}$, is determined from equation (1).

Insert Table II about here

We comment on several outcomes. First, as the mean level of confidence increases, more entrepreneurs enter the market (line 1). Second, excess entry (the probability of failure given entry) occurs even in underconfident populations and increases as population 
overconfidence increases (line 2). In particular, when the population presents the most extreme case of underconfidence that we examine, $\mathrm{E}[X]-\mathrm{E}[Y]=-0.9$ (left column within each panel), excess entry amounts to $15.3 \%$ of entrants in the largest market (left panel) and $22.4 \%$ of entrants in the smallest market (right panel).

In the largest market, entrants coming from underconfident populations underestimate their skill (left panel, line 5, first two columns). In more stringent markets, most entrants overestimate their skill even when they come from underconfident, on average, populations (central and right panels, lines 4 and 5, first two columns). The implication of this result is that drawing general inferences regarding entrepreneurial overconfidence based on surveys of entrepreneurs active in only stringent markets may be misleading.

Interestingly, the proportions of missed opportunities drop significantly as the population, on average, becomes more overconfident (line 3). In particular, when average miscalibration changes from extreme underconfidence to extreme overconfidence, missed opportunities decrease by $52 \%$ (56.1 to 26.7) in our largest market (left panel) and by $19 \%$ (15.8 to 12.8) in our smallest market (right panel). One intuitive implication of this result might be to advise potential entrepreneurs to boost their confidence in order to reduce missed opportunities and thereby increase social welfare. However, this would not be wise. Greater overconfidence implies not only less missed opportunities but also more failures (line 2). Reducing judgmental fallibility, however, decreases both missed opportunities and failures (Table I).

Overall, the remarkable feature of Table II is that excess entry can be observed even in the presence of systematic underconfidence in the population of potential entrepreneurs and even when both successful entrants and failures are underconfident. Enhancing entrepreneurial overconfidence decreases missed opportunities but at the cost of increased failures. One way to decrease both is to reduce skill uncertainty by mitigating judgmental fallibility.

Summary. In short, the model suggests that, with or without systematic overconfidence, excess entry simply follows from people acting on estimates of their skill that are imperfectly related to their true skill. Moreover, the amount of observable excess entry is a complex function of the different parameters identified in our model, that is, signal validity $\left(\rho_{x y}\right)$, the entry decision cut-off $\left(x_{c}\right)$, the market (success) cut-off $\left(y_{c}\right)$, and overconfidence in the population $(\mathrm{E}[X]-\mathrm{E}[Y])$, if any. Thus, from any empirical study, it is difficult to prove or 
disprove that overconfidence drives the excess entry phenomenon. As the above simulations show, excess entry can be observed even when all entrants are on average underconfident.

Our model implies that failures exhibit greater confidence than successful entrants. In terms of empirical evidence, Koellinger et al. (2007) do indeed report a negative relation between entrepreneurial confidence and survival chances. In the case of $\mathrm{Wu}$ and Knott's (2006) study of banking, evidence of overplacement is heavily dependent on observing failures (see Wu \& Knott, 2006, p. 1321). However, as we have shown, the confidencesurvival relation can be observed whether or not the population of entrepreneurs is - on average - overconfident. Moreover, surveys that document apparently overconfident entrepreneurs (e.g., Cooper et al., 1988) suffer from selection bias in that respondents typically exclude people who have decided not to take entrepreneurial actions.

Our model further suggests that overconfidence among active entrepreneurs will be especially great in conditions of high skill uncertainty, e.g., after technological or product changes. At the very least, the model provides directions for empirical researchers to investigate what drives excess entry - and when.

\section{Discussion}

We have shown that, in the absence of systematic overconfidence in a population of entrepreneurs and, even in the presence of systematic underconfidence, an imperfect relation between estimated and true ability is sufficient to produce observable excess entry.

Our analytical results are the consequence of two pervasive phenomena. One is the presence of irreducible error in judgment and the other the fact that people take actions based on fallible judgment. What is surprising is that people don't recognize the joint effects of the two phenomena. At the individual level, it has been shown that these two factors can induce people to have unwarranted confidence in their judgments (Einhorn and Hogarth 1978). At the same time, ignoring their impact, many studies assert that entrepreneurs are overconfident. Paradoxically, the very factors that some social scientists have identified as leading people to be overconfident in their judgments are the same as those that others ignore in asserting that entrepreneurs are overconfident. (For related phenomena, see Denrell 2003, 2005).

We have shown analytically that judgmental fallibility produces self-selection in that entrepreneurs who take risks by acting on beliefs about their own skill are, on average, more confident (but not necessarily overconfident) than those who take no action. This result echoes the empirical evidence by Koellinger et al. (2007) who concluded that 
(over)confidence in one's own entrepreneurial skills largely determines the decision to start a new business. At the same time, we have shown that entry (and excess entry) can occur even if the population of entrepreneurs is, on average, underconfident. Moreover, Koellinger et al. (2007) (and many other empirical studies) measured entrepreneurial self-confidence and not overconfidence and so to conclude that overconfidence is driving entry is imprecise, to say the least. As we have shown, those who decide to start a new business always exhibit greater confidence than non-entrants, even when both groups are on average underconfident. Excess entry can result simply from imperfect judgment involving random errors rather than a systematic bias.

We have also shown that in some circumstances (particularly stringent markets), entrepreneurs should act on the basis of imperfectly valid signals and thus, in market entry experiments of the type conducted by Camerer and Lovallo (1999), it is inappropriate to infer overconfidence from observing higher entry rates in "skill" as opposed to "random" conditions.

Our results support the useful distinctions made by Moore and Healy (2008) between three different types of overconfidence: overestimation, overplacement, and overprecision. Our analytical model shows that different types of confidence do not necessarily occur simultaneously. There is growing awareness in the literature of the need to recognize the different ways in which people can be overconfident (Wu and Knott 2006; Hilton 2007).

An important issue centers on the costs and benefits of overconfidence. Bonnefon, Hilton, and Molian (2006) provide an intriguing result that suggests a positive relation between success as an entrepreneur and being appropriately calibrated when assessing uncertainty (i.e., lack of overprecision). In a group of entrepreneurs attending a management course, the more successful entrepreneurs exhibited less overconfidence in an experimental task. Biais and Weber (2007) have further demonstrated a relation between amount of hindsight bias and performance by investment bankers. The better performing bankers exhibit less bias. Similarly, Fenton-O'Creevy et al. (2003) gave a test to financial traders designed to measure susceptibility to the "illusion of control" (Langer 1975). They found that the less susceptible earned higher performance-related pay.

Our analytical results show that successful entrepreneurs are less overconfident than failures and this is consistent with empirical evidence. Duchesneau and Gartner (1990), for example, conducted a field study of an emerging industry with high uncertainty and found that lead entrepreneurs in unsuccessful companies relied less on outside professional and advisors and believed that they had more control of their success in business than successful 
entrepreneurs. Similarly, Koellinger et al. (2007) concluded that countries with a high rate of entrepreneurial self-confidence have more start-ups and lower average survival chances. Finally, Wu and Knott (2006) found evidence of greater overplacement among failures than among successes. On the other hand, none of these results means that excess entry is due to overconfidence. In fact, our model suggests that excess entry can occur even when all potential entrepreneurs are underconfident. Another important result of our model is that overconfidence can have two different effects. It reduces both missed opportunities and the success rate of entrepreneurs who decide to enter the market.

An important implication of our model relates to the conditions under which a new market will result in equilibrium in the sense that there is no excess entry. Consider a set up similar to Camerer and Lovallo (1999) where market capacity is limited (only $c$ of $N$ participants can enter). Here, equilibrium can only be achieved if either (a) signal validity is perfect $\left(\rho_{\mathrm{xy}}=1.0\right)$ such that potential entrants know for sure whether or not they should enter, or (b) when signal validity is imperfect $\left(\rho_{\mathrm{xy}}<1.0\right)$, the number of entrants who fail to enter but who should have is matched exactly by the number who enter but who should not have in other words when individual errors cancel each other out. However, one would only expect to see the latter occur when potential entrants perceive that the economic consequences of the two types of error are equal. It is not clear that this will generally be the case and thus the only way to reduce excess entry is to increase signal validity (i.e., decrease skill uncertainty).

Our work questions whether the psychological explanation of overconfidence accounts for excess entry. It is tempting to think, therefore, that the economic theory of risk-taking is sufficient to explain the phenomenon and to conclude at this point. However, we do not believe this would be wise. First, it would be problematic to disconfirm the economic theory by empirical data because observations of excess entry could be easily rationalized after the fact. Second, the economic explanation provides little or no insight into how potential entrepreneurs appraise the risks they face nor how they judge whether these risks are acceptable. And third, it provides no clues as to how entrepreneurs might better assess risks.

Instead, we believe that an examination of the types and sources of confidence that influence entry decisions can be most instructive. Following the lead of Moore and Healy (2008), we have in this paper considered differences between types of confidence judgments, that is, estimation and placement. We suspect that for many traits or abilities, estimation judgments are fairly easy to make (and possibly plausibly accurate) if they relate to a 
person's past experiences (e.g., you can estimate how well you do something if you have done it - or something similar - several times before). On the other hand, placement judgments strike us as being much more difficult as we necessarily know more about our own abilities than those of others. Thus, unless we are able to assume that we are just like others, it is not clear how people can make these judgments accurately. Indeed, in both a field study of entrepreneurs and a laboratory study involving students playing a market-entry game, Moore et al. (2007) showed evidence of what they called "myopic self-focus." When considering market-entry decisions participants paid disproportionate attention to their own internal characteristics and little to those of competitors or the external market in general. As Moore et al. (2007) wisely suggest, much could be gained by helping potential market entrants investigate external conditions more thoroughly.

It is sometimes said that, whereas overconfidence is dysfunctional for individual entrepreneurs, it is functional for society in that many individual failures are necessary to achieve success at the societal level. We disagree. As we have shown, greater overconfidence implies less missed opportunities but also more failures. Skill uncertainty or judgmental fallibility plays an important role in why entrepreneurs enter businesses that fail. However, it also plays a role in why people fail to enter businesses they should have entered. Reducing skill uncertainty diminishes both missed opportunities and failures. Society would be better off as a whole if entrepreneurs were better able to estimate their abilities in both absolute and relative terms. However, this is not the same as saying excess entry is due to overconfidence.

The main implication of our work is to emphasize the importance of training potential entrepreneurs to reduce skill uncertainty. Whereas we have no precise "formula for success," we speculate that the basis of such training should follow principles relevant to the acquisition of expertise. These involve, principally, total immersion in the domain of activity and learning to improve performance through continued practice with appropriate feedback (see, e.g., Ericsson and Charness 1994). However, this is not something that can be achieved in a short period of time. In the case of potential entrepreneurs, we believe it would involve in addition to acquiring basic business skills - detailed studies of the specific industry of interest and many experiential exercises involving accurate feedback that can increase the entrepreneur's awareness of her skill set - both in isolation and in comparison with others as well as indicating paths to improvement. Just how to organize such educational experiences is an important challenge for society.

Finally, we conclude with implications of our work for venture capitalists. As is well known, venture capitalists rely on their own beliefs about the characteristics of a potentially 
successful business when assessing new entrepreneurial proposals. The most important block of selection criteria appears to be the management team, one component of which is the entrepreneur's self-confidence (Riquelme and Watson 2002). Indeed, one study documented the entrepreneur's "desire for success" as the most important selection criterion (Khan 1987). And yet, in this study the entrepreneur's competence in the field of endeavor was not a significant predictor of venture capitalists' judgments. More generally, we suspect that being ambitious and willing to succeed is important for success, but that "desire for success" alone is rarely sufficient. In fact, in Khan's (1987) study, "desire for success" was negatively related to the actual outcomes of the ventures. And as shown above, high confidence is not a good predictor of success. ${ }^{6}$ We suggest, therefore, that venture capitalists will make better decisions if they do not equate confidence with skill and experience and, from time to time, sample from less confident entrepreneurs. However uncomfortable it may be at the moment of the decision, it may lead to revising erroneous implicit models of project selection as well as discovering unexpected talents.

\footnotetext{
${ }^{6}$ In fact, venture capitalists themselves are overconfident. Zacharakis and Shepherd (2001) documented that $96 \%$ of 51 Silicon Valley venture capitalists that participated in their study overestimated their ability to predict the success of new ventures. In addition, more overconfident venture capitalists were less accurate in their decisions.
} 


\section{Appendix}

\section{When does market entry take place? The cut-off for the entrepreneur's decision, $x_{c}$.}

Entrepreneur $i$ will choose to enter the market if her estimated skill to succeed in this market is greater than the cut-off $x_{c}$. The cut-off $x_{c}$ is determined by solving the indifference equation (1) for $x_{i}$.

The parameters required to solve the equation are: (1) $\mathrm{E}[Y]$ and $\sigma_{y}$, the parameters of the distribution of true skill; (2) $\mathrm{E}[X]$ and $\sigma_{x}$, the parameters of the distribution of estimated skill; (3) $\rho_{x y}$, the correlation between true and estimated skills (signal validity or skill uncertainty); (4) $y_{c}$, the success cut-off point; and (5) $K$, the cost of entry. In what follows, we assume that both $X$ and $Y$ are $\mathrm{N}(0,1)$.

By varying the cost of entry, $K$, we illustrate three scenarios, with $K=0.1,0.4$, and 1.0. Within each scenario, we vary both signal validity, $\rho_{x y}$ and the success cut-off percentile, $y_{c}$. To find numerically the solution of equation (1), we calculate the value of its left hand side, $-K \int_{-\infty}^{y_{c}} f_{Y \mid X}\left(y \mid x_{i}\right) d y+\int_{y_{c}}^{\infty}\left(y-y_{c}-K\right) f_{Y \mid X}\left(y \mid x_{i}\right) d y$, for all values of $x_{i}$ within the range of $\mathrm{E}[X] \pm 3 \sigma_{x}$, i.e., for $x_{i} \in[-3 ; 3]$. We use the solution of equation (1), $x_{c}^{*}$ to find the probability of entry, $P\left\{x>x_{c}^{*}\right\}$.

The results are presented in Figure I in the main text where the curves depict the probability of entry as a function of $\rho_{x y}$. One curve corresponds to each level of $y_{c}$. Within each cost scenario (represented by the three panels), there are several similar trends. First, at higher $y_{c}$-percentiles (i.e., less successes can be accommodated by the market), the probability of entry decreases. That is, there are fewer entrants in more stringent markets. Second, larger $\rho_{x y}$ implies more entry in stringent markets (i.e., high $y_{c}$-percentiles). In less stringent markets (i.e., low $y_{c}$-percentiles), larger $\rho_{x y}$ leads to less entry. In addition, the critical point of $y_{c}$ at which the effect of $\rho_{x y}$ on the probability of entry reverses depends on the cost of entry decision $(K)$. When the cost of entry is higher, less skill uncertainty implies more entry for a wider range of markets. In our example, when $K=0.1$ (left panel), the positive effect of $\rho_{x y}$ on entry is observed only in more stringent markets - starting at the $90^{\text {th }}$ 
percentile of $y_{c}$. When $K=1.0$ (right panel), this positive effect is observed in all markets starting at the $21^{\text {st }}$ percentile of $y_{c}$.

Finally, the overall effect of a larger cost of entry, $K$, is to decrease entry. 


\section{REFERENCES}

Alpert, Marc, and Howard Raiffa. 1982. "A Progress Report on the Training of Probability Assessors." In Judgment under Uncertainty: Heuristics and Biases, ed. Daniel Kahneman, Paul Slovic, and Amos Tversky, 294-305. Cambridge, UK: Cambridge University Press.

Bernardo, Antonio E., and Ivo Welch. 2001. "On the Evolution of Overconfidence and Entrepreneurs." Journal of Economics and Management Strategy, 10(3): 301-330.

Biais, Bruno, and Martin Weber. 2007. "Hindsight Bias and Investment Performance.” IDEI Working Paper No. 476.

Bonnefon, Jean-François, Denis J. Hilton, and D. Molina. 2006. "A Portrait of the Unsuccessful Entrepreneur as a Miscalibrated Thinker: Profit-decreasing Ventures are Run by Overconfident Owners". CNRS working paper No.

Brockhaus, Robert H. Sr. 1980. "Risk Taking Propensity of Entrepreneurs.” The Academy of Management Journal, 23(3): 509-520.

Burson, Katherine A., Richard P. Larrick, and Joshua Klayman. 2006. "Skilled or Unskilled, but still Unaware of It: How Perceptions of Difficulty Drive Miscalibration in Relative Comparisons." Journal of Personality and Social Psychology, 90(1): 60-77.

Camerer, Colin F., and Dan Lovallo. 1999. "Overconfidence and Excess Entry: An Experimental Approach.” American Economic Review, 89(1): 306-318.

Cooper, Arnold C., Carolyn Y. Woo, and William C. Dunkelberg. 1988. "Entrepreneurs' Perceived Chances for Success." Journal of Business Venturing, 2: 97-108.

Dawes, Robyn M., and Matthew Mulford. 1996. "The False Consensus Effect and Overconfidence: Flaws in Judgment, or Flaws in How We Study Judgment?" Organizational Behavior and Human Decision Processes, 65: 201-211.

Dennis, William J. 1997. "More than You Think: An Inclusive Estimate of Business Entries." Journal of Business Venturing. 12: 175-196.

Denrell, Jerker. 2003. "Vicarious Learning, Under-sampling of Failure, and the Myths of Management." Organization Science, 14(3): 227-243.

Denrell, Jerker. 2005. "Why Most People Disapprove of Me: Experience Sampling in Impression Formation.” Psychological Review, 112(4): 951-978.

Duchesneau, Donald A., and William B. Gartner. 1990. “A Profile of New Venture Success and Failure in an Emerging Industry." Journal of Business Venturing, 5(5): 297-312.

Einhorn, Hillel J., and Robin M. Hogarth. 1978. "Confidence in Judgment: Persistence of the Illusion of Validity." Psychological Review, 85: 395-416. 
Erev, Ido, Thomas S. Wallsten, and David V. Budescu. 1994. "Simultaneous Over- and Underconfidence: The Role of Error in Judgment Processes." Psychological Review, 101: $519-527$.

Ericsson, K. Anders, and Neil Charness. 1994. "Expert Performance: Its Structure and Acquisition." American Psychologist, 49: 725-747.

Fenton-O'Creevy, Mark, Nigel Nicholson, Emma Soane, and Paul Willman. 2003. "Trading on Illusions: Unrealistic Perceptions of Control and Trading Performance." Journal of Occupational and Organizational Psychology, 76: 53-68.

Geroski, Paul A. 1995. "What do We Know about Entry?” International Journal of Industrial Organization, 13: 421-440.

Headd, Brian. 2003. "Redefining Business Success: Distinguishing between Closure and Failure.” Small Business Economics, 21: 51-61.

Hilton, Denis. 2007. "Overconfidence, Trading, and Entrepreneurship: Cognitive and Cultural Processes in Risk-taking." In Cognitive Economics: New Trends, ed. Richard Topol and Bernard Walliser, 225-235. Amsterdam: Elsevier Press.

Hoelzl, Erik, and Aldo Rustichini. 2005. “Overconfident: Do You Put Your Money on It?” Economic Journal, 115: 305-318.

Jovanovich, Boyan. 1982. "Selection and the Evolution of Industry." Econometrica, 50(3): $649-670$.

Kahneman, Daniel, Paul Slovic, and Amos Tversky, ed. 1982. Judgment under Uncertainty:

Heuristics and Biases. Cambridge, UK: Cambridge University Press.

Khan, Arshad M. 1987. "Assessing Venture Capital Investments with Noncompensatory Behavioral Decision Models.” Journal of Business Venturing, 2(3): 193-205.

Klayman, Joshua, Jack B. Soll, Claudia Gonzalez-Vallejo, and Sema Barlas. 1999. "Overconfidence: It Depends on How, What and Whom You Ask." Organizational Behavior and Human Decision Processes, 79(3): 216-247.

Klepper, Steven. 1996. "Entry Exit, Growth and Innovation over the Product Cycle." American Economic Review, 86(3): 562-583.

Koellinger, Philipp, Maria Minniti, and Christian Schade. 2007. "I Think I Can, I Think I Can": Overconfidence and Entrepreneurial Behavior." Journal of Economic Psychology, 28: 502-527.

Kruger, Justin. 1999. "Lake Wobegon Be Gone! The "Below-average Effect" and the Egocentric Nature of Comparative Ability Judgments." Journal of Personality and Social Psychology, 77(2): 221-232. 
Langer, Ellen J. 1975. "The Illusion of Control." Journal of Personality and Social Psychology, 32(2): 311-328.

Masters, Robert, and Robert Meier. 1988. "Sex Differences and Risk-taking Propensity of Entrepreneurs.” Journal of Small Business Management, 26(1): 31-35.

Miner, John B., and Nambury S. Raju. 2004. "Risk Propensity Differences between Managers and Entrepreneurs and between Low- and High-growth Entrepreneurs: A Reply in a More Conservative Vein.” Journal of Applied Psychology, 89(1): 3-13.

Moore, Don A., and Daylian M. Cain. 2007. "Overconfidence and Underconfidence: When and Why People Underestimate (and Overestimate) the Competition." Organizational Behavior and Human Decision Processes, 103: 197-213.

Moore, Don A., and Paul J. Healy. 2008. "The Trouble with Overconfidence.” Psychological Review, 115(2): 502-517.

Moore, Don A., John M. Oesch, and Charlene Zietsma. 2007. "What Competition? Myopic Self-focus in Market-entry Decisions.” Organization Science, 18(3): 440-454.

Norton, William I. Jr., and William T. Moore. 2002. "Entrepreneurial Risk: Have We Been Asking the Wrong Question?” Small Business Economics, 18(4): 281-287.

Palich, Leslie E., and D. Ray Bagby. 1995. "Using Cognitive Theory to Explain Entrepreneurial Risk-taking: Challenging Conventional Wisdom." Journal of Business Venturing, 10: 425-438.

Riquelme, Heman, and John Watson. 2002. "Do Venture Capitalists' Implicit Theories on New Business Success/Failure Have Empirical Validity?” International Small Business Journal, 20: 395-420.

Sarasvathy, D. K., Herbert A. Simon, and Lester Lave. 1998. "Perceiving and Managing Business risks: Differences between Entrepreneurs and Bankers." Journal of Economic Behavior and Organization, 33(2): 207-225.

Svenson, Ola. 1981. “Are We All Less Risky and More Skillful than Our Fellow Drivers?" Acta Psychologica, 47: 143-148.

Wu, Brian, and Anne Marie Knott. 2006. "Entrepreneurial Risk and Market Entry." Management Science, 52: 1315-1330.

Zacharakis, Andrew L., and Dean A. Shepherd. 2001. "The Nature of Information and Overconfidence on Venture Capitalists Decision Making." Journal of Business Venturing, 16(4): 311-332. 
Table I: The Effect of the Correlation between Estimated and True Skill $\left(\rho_{x y}\right)$.

\begin{tabular}{|c|c|c|c|c|c|c|c|c|c|c|c|c|c|c|c|c|}
\hline \multicolumn{7}{|c|}{$y_{c}=-0.5(31 \%)$} & \multicolumn{5}{|c|}{$y_{c}=0.5(69 \%)$} & \multicolumn{5}{|c|}{$y_{c}=1.0(84 \%)$} \\
\hline & $\rho_{x y}$ & 0.0 & 0.3 & 0.5 & 0.7 & 0.9 & 0.0 & 0.3 & 0.5 & 0.7 & 0.9 & 0.0 & 0.3 & 0.5 & 0.7 & 0.9 \\
\hline & $x_{c} *(1)$ & -3.0 & -1.5 & -0.8 & -0.4 & -0.2 & 3.0 & 1.8 & 1.2 & 1.0 & 0.9 & 3.0 & 3.0 & 2.2 & 1.7 & 1.5 \\
\hline 1 & Proportion entering market, $\%$ & 99.9 & 93.8 & 78.5 & 66.3 & 56.8 & 0.1 & 3.7 & 11.3 & 15.6 & 17.4 & 0.1 & 0.1 & 1.4 & 4.3 & 6.7 \\
\hline 2 & Proportion of excess entry (failures), $\%$ & 30.9 & 29.4 & 23.5 & 15.0 & 4.0 & 69.5 & 43.5 & 35.0 & 23.2 & 6.9 & 84.4 & 49.9 & 37.5 & 26.1 & 8.0 \\
\hline 3 & Proportion missed opportunities, $\%$ & 69.2 & 46.2 & 42.2 & 38.0 & 34.0 & 30.9 & 29.9 & 26.5 & 22.3 & 17.7 & 15.9 & 15.8 & 15.2 & 13.3 & 10.4 \\
\hline \multicolumn{17}{|c|}{4 Proportion of overestimation (\%) among: } \\
\hline & All potential entrants & 50.0 & 50.0 & 50.0 & 50.0 & 50.0 & 50.0 & 50.0 & 50.0 & 50.0 & 50.0 & 50.0 & 50.0 & 50.0 & 50.1 & 50.0 \\
\hline & Entrants & 50.1 & 52.8 & 57.5 & 58.7 & 56.3 & 99.9 & 94.1 & 83.1 & 73.6 & 63.2 & 99.9 & 98.9 & 92.7 & 81.2 & 67.1 \\
\hline & Non-entrants & 0.1 & 8.1 & 22.5 & 32.9 & 41.8 & 49.9 & 48.3 & 45.8 & 45.6 & 47.2 & 49.9 & 49.9 & 49.4 & 48.7 & 48.8 \\
\hline & Successful entrants & 34.6 & 39.0 & 45.5 & 51.5 & 54.5 & 99.8 & 89.5 & 73.9 & 65.7 & 60.5 & 99.6 & 97.9 & 88.3 & 74.5 & 64.2 \\
\hline & Excess entrants (failures) & 84.7 & 85.9 & 96.9 & 100.0 & 100.0 & 100.0 & 100.0 & 100.0 & 100.0 & 100.0 & 100.0 & 100.0 & 100.0 & 100.0 & 100.0 \\
\hline \multicolumn{17}{|c|}{5 Average difference between estimated and true skill ${ }^{(2)}$ among: } \\
\hline & All potential entrants & 0.0 & 0.0 & 0.0 & 0.0 & 0.0 & 0.0 & 0.0 & 0.0 & 0.0 & 0.0 & 0.0 & 0.0 & 0.0 & 0.0 & 0.0 \\
\hline & Entrants & 0.0 & 0.1 & 0.2 & 0.2 & 0.1 & 3.3 & 1.5 & 0.9 & 0.5 & 0.1 & 3.3 & 2.3 & 1.3 & 0.6 & 0.2 \\
\hline & Non-entrants & -3.3 & -1.4 & -0.7 & -0.3 & -0.1 & 0.0 & -0.1 & -0.1 & -0.1 & 0.0 & 0.0 & 0.0 & 0.0 & 0.0 & 0.0 \\
\hline & Successful entrants & -0.5 & -0.3 & -0.1 & 0.0 & 0.0 & 2.1 & 0.9 & 0.4 & 0.2 & 0.1 & 1.8 & 1.5 & 0.8 & 0.4 & 0.1 \\
\hline & Excess entrants (failures) & 1.1 & 1.0 & 1.1 & 1.0 & 0.8 & 3.8 & 2.4 & 1.7 & 1.3 & 0.8 & 3.6 & 3.0 & 2.1 & 1.4 & 0.9 \\
\hline \multirow[t]{6}{*}{6} & Proportion of overplacement (relative to $y$ & c) $(\%)$ & among: & & & & & & & & & & & & & \\
\hline & All potential entrants & 21.4 & 17.5 & 14.5 & 11.1 & 6.3 & 21.3 & 17.4 & 14.5 & 11.1 & 6.3 & 13.4 & 11.3 & 9.6 & 7.5 & 4.3 \\
\hline & Entrants & 21.4 & 18.6 & 18.5 & 15.0 & 4.0 & 69.5 & 43.5 & 35.0 & 23.2 & 6.9 & 84.4 & 49.9 & 37.5 & 26.1 & 8.0 \\
\hline & Non-entrants & 0.0 & 0.0 & 0.0 & 3.4 & 9.3 & 21.3 & 16.4 & 11.9 & 8.9 & 6.2 & 13.3 & 11.3 & 9.2 & 6.7 & 4.1 \\
\hline & Successful entrants & 0.0 & 0.0 & 0.0 & 0.0 & 0.0 & 0.0 & 0.0 & 0.0 & 0.0 & 0.0 & 0.0 & 0.0 & 0.0 & 0.0 & 0.0 \\
\hline & Excess entrants (failures) & 69.3 & 63.4 & 78.8 & 100.0 & 100.0 & 100.0 & 100.0 & 100.0 & 100.0 & 100.0 & 100.0 & 100.0 & 100.0 & 100.0 & 100.0 \\
\hline \multicolumn{17}{|c|}{ 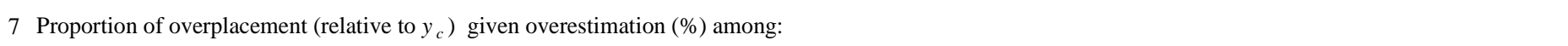 } \\
\hline & All potential entrants & 42.7 & 34.9 & 29.1 & 22.1 & 12.6 & 42.7 & 34.9 & 29.0 & 22.2 & 12.7 & 26.7 & 22.7 & 19.2 & 15.0 & 8.6 \\
\hline & Entrants & 42.7 & 35.3 & 32.2 & 25.5 & 7.2 & 69.6 & 46.3 & 42.1 & 31.5 & 10.9 & 84.4 & 50.4 & 40.5 & 32.1 & 11.9 \\
\hline & Non-entrants & 0.0 & 0.0 & 0.0 & 10.4 & 22.3 & 42.6 & 34.0 & 26.0 & 19.5 & 13.1 & 26.6 & 22.6 & 18.7 & 13.7 & 8.3 \\
\hline & Successful entrants & 0.0 & 0.0 & 0.0 & 0.0 & 0.0 & 0.0 & 0.0 & 0.0 & 0.0 & 0.0 & 0.0 & 0.0 & 0.0 & 0.0 & 0.0 \\
\hline & Excess entrants (failures) & 81.7 & 73.8 & 81.4 & 100.0 & 100.0 & 100.0 & 100.0 & 100.0 & 100.0 & 100.0 & 100.0 & 100.0 & 100.0 & 100.0 & 100.0 \\
\hline
\end{tabular}

Notes:

(1) $x_{c}$ is the entry decision cut-off, $y_{c}$ is the success cut-off, and $\rho_{x y}$ is signal validity. At $x_{c}{ }^{*}$ the expected payoff of entry is zero. $X$ is estimated skill, $Y$ is true skill. Both are $\mathrm{N}(0,1)$.

(2) Positive values indicate overestimation, negative values indicate underestimation.

(3) In this example, cost of entry, $K$ is 0.1 . 
Table II: The Effect of Confidence at the Level of the Population, $\mathrm{E}(X)$.

\begin{tabular}{|c|c|c|c|c|c|c|c|c|c|c|c|c|c|c|c|c|}
\hline & & & $y_{c}=$ & -0.5( & 1\%) & & & $y_{c}=$ & $=0.5(6$ & $\%)$ & & & $y_{c}$ & $=1.0(8$ & $4 \%)$ & \\
\hline & $\mathrm{E}[X]$ & -0.9 & -0.5 & 0.0 & 0.5 & 0.9 & -0.9 & -0.5 & 0.0 & 0.5 & 0.9 & -0.9 & -0.5 & 0.0 & 0.5 & 0.9 \\
\hline & $x_{c} *^{(1)}$ & -0.8 & -0.8 & -0.8 & -0.8 & -0.8 & 1.2 & 1.2 & 1.2 & 1.2 & 1.2 & 2.2 & 2.2 & 2.2 & 2.2 & 2.2 \\
\hline 1 & Proportion entering market, $\%$ & 45.6 & 61.4 & 78.5 & 90.2 & 95.4 & 1.7 & 4.4 & 11.3 & 23.8 & 37.9 & 0.1 & 0.3 & 1.4 & 4.4 & 9.5 \\
\hline 2 & Proportion of excess entry (failures), $\%$ & 15.3 & 19.1 & 23.5 & 27.0 & 28.8 & 20.2 & 26.4 & 34.9 & 43.6 & 50.1 & 22.4 & 28.3 & 37.6 & 47.2 & 55.1 \\
\hline 3 & Proportion missed opportunities, $\%$ & 56.1 & 50.4 & 42.2 & 33.4 & 26.7 & 30.0 & 28.9 & 26.4 & 22.8 & 19.2 & 15.8 & 15.7 & 15.2 & 14.2 & 12.8 \\
\hline 4 & Proportion of overestimation (\%) among: & & & & & & & & & & & & & & & \\
\hline & All potential entrants & 18.4 & 30.8 & 50.0 & 69.2 & 81.6 & 18.4 & 30.9 & 50.0 & 69.1 & 81.6 & 18.4 & 30.9 & 50.0 & 69.2 & 81.6 \\
\hline & Entrants & 30.4 & 41.7 & 57.5 & 73.1 & 83.4 & 64.7 & 73.6 & 83.0 & 90.0 & 93.9 & 81.2 & 87.4 & 92.7 & 96.2 & 97.8 \\
\hline & Non-entrants & 8.4 & 13.6 & 22.5 & 33.5 & 43.3 & 17.6 & 28.9 & 45.8 & 62.6 & 74.1 & 18.3 & 30.7 & 49.4 & 68.0 & 79.9 \\
\hline & Successful entrants & 19.2 & 29.2 & 45.5 & 63.7 & 77.0 & 55.8 & 64.1 & 73.9 & 82.2 & 87.9 & 75.8 & 82.4 & 88.3 & 92.8 & 95.2 \\
\hline & Excess entrants (failures) & 92.2 & 94.5 & 96.8 & 98.4 & 99.2 & 100.0 & 100.0 & 100.0 & 100.0 & 100.0 & 100.0 & 100.0 & 100.0 & 100.0 & 100.0 \\
\hline 5 & Average difference between estimated and t & ue skil & amon & & & & & & & & & & & & & \\
\hline & All potential entrants & -0.9 & -0.5 & 0.0 & 0.5 & 0.9 & -0.9 & -0.5 & 0.0 & 0.5 & 0.9 & -0.9 & -0.5 & 0.0 & 0.5 & 0.9 \\
\hline & Entrants & -0.5 & -0.2 & 0.2 & 0.6 & 1.0 & 0.3 & 0.6 & 0.8 & 1.1 & 1.4 & 0.8 & 1.0 & 1.3 & 1.6 & 1.8 \\
\hline & Non-entrants & -1.3 & -1.0 & -0.7 & -0.4 & -0.2 & -0.9 & -0.5 & -0.1 & 0.3 & 0.6 & -0.9 & -0.5 & 0.0 & 0.5 & 0.8 \\
\hline & Successful entrants & -0.7 & -0.4 & -0.1 & 0.3 & 0.7 & 0.0 & 0.2 & 0.4 & 0.6 & 0.8 & 0.5 & 0.6 & 0.8 & 0.9 & 1.1 \\
\hline & Excess entrants (failures) & 0.7 & 0.8 & 1.1 & 1.3 & 1.6 & 1.5 & 1.6 & 1.7 & 1.8 & 2.0 & 1.9 & 2.0 & 2.1 & 2.2 & 2.4 \\
\hline 6 & Proportion of overplacement (relative to $y_{c}$ ) & $(\%)$ an & ong: & & & & & & & & & & & & & \\
\hline & All potential entrants & 4.3 & 8.2 & 14.5 & 21.1 & 25.3 & 2.6 & 6.1 & 14.5 & 27.3 & 39.0 & 1.3 & 3.4 & 9.6 & 21.1 & 33.8 \\
\hline & Entrants & 9.5 & 13.3 & 18.5 & 23.4 & 26.5 & 20.2 & 26.4 & 34.9 & 43.6 & 50.1 & 22.4 & 28.3 & 37.6 & 47.2 & 55.1 \\
\hline & Non-entrants & 0.0 & 0.0 & 0.0 & 0.0 & 0.0 & 2.2 & 5.2 & 11.9 & 22.2 & 32.3 & 1.2 & 3.4 & 9.2 & 19.9 & 31.5 \\
\hline & Successful entrants & 0.0 & 0.0 & 0.0 & 0.0 & 0.0 & 0.0 & 0.0 & 0.0 & 0.0 & 0.0 & 0.0 & 0.0 & 0.0 & 0.0 & 0.0 \\
\hline & Excess entrants (failures) & 62.4 & 69.7 & 78.7 & 86.9 & 92.0 & 100.0 & 100.0 & 100.0 & 100.0 & 100.0 & 100.0 & 100.0 & 100.0 & 100.0 & 100.0 \\
\hline 7 & Proportion of overplacement (relative to $y_{c}$ ) & given & veresti & nation & \%) am & & & & & & & & & & & \\
\hline & All potential entrants & 23.6 & 26.4 & 29.0 & 30.5 & 31.0 & 13.9 & 19.8 & 29.0 & 39.5 & 47.8 & 6.8 & 11.2 & 19.2 & 30.5 & 41.4 \\
\hline & Entrants & 31.4 & 31.9 & 32.1 & 32.0 & 31.8 & 31.2 & 35.9 & 42.0 & 48.4 & 53.3 & 27.6 & 32.4 & 40.6 & 49.1 & 56.3 \\
\hline & Non-entrants & 0.0 & 0.0 & 0.0 & 0.0 & 0.0 & 12.7 & 18.0 & 26.0 & 35.5 & 43.6 & 6.7 & 11.0 & 18.7 & 29.3 & 39.5 \\
\hline & Successful entrants & 0.0 & 0.0 & 0.0 & 0.0 & 0.0 & 0.0 & 0.0 & 0.0 & 0.0 & 0.0 & 0.0 & 0.0 & 0.0 & 0.0 & 0.0 \\
\hline & Excess entrants (failures) & 67.7 & 73.7 & 81.3 & 88.2 & 92.7 & 100.0 & 100.0 & 100.0 & 100.0 & 100.0 & 100.0 & 100.0 & 100.0 & 100.0 & 100.0 \\
\hline
\end{tabular}

\section{Notes:}

(1) $x_{c}$ is the entry decision cut-off and $y_{c}$ is the success cut-off. At $x_{c} *$ the expected payoff of entry is zero. $X$ is estimated skill, $Y$ is true skill. $X$ is $\mathrm{N}(\mathrm{E}[X], 1)$; $\mathrm{Y}$ is $\mathrm{N}(0,1)$.

(2) Positive values indicate overestimation, negative values indicate underestimation.

(3) In this example, signal validity, $\rho_{x y}$ is 0.5 , and cost of entry, $K$ is 0.1. 
Figure I: The Effect of the Success Cut-Off $\left(Y_{c}\right)$ and the Correlation between Estimated and True Ability $\left(\rho_{x y}\right)$ on the Probability of Entry.
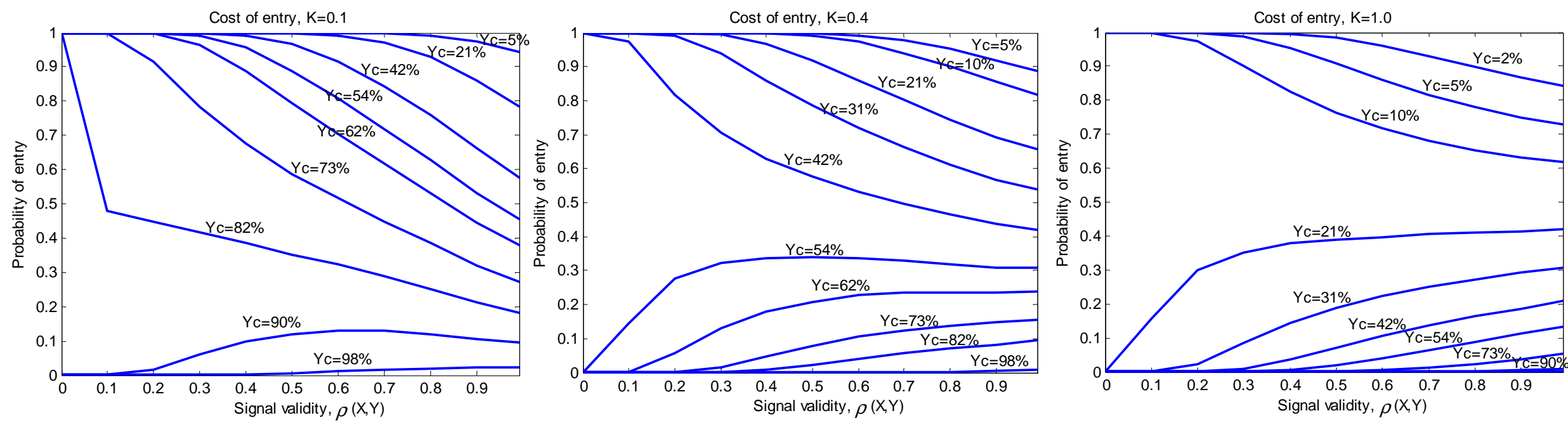

Note: $Y_{c}$ is the success cut-off percentile. 